\title{
Comparison of land-cover change and climate variability impacts on runoff using hydrological modelling and sensitivity-based approaches
}

\author{
Jai Vaze', Yongqiang Zhang ${ }^{1}$ and Huiyun $\mathrm{Li}^{2}$ \\ ${ }^{1}$ Water for a Healthy Country Flagship, CSIRO Land and Water, GPO BOX 1666, Canberra ACT 2601, \\ Australia. \\ ${ }^{2}$ Faculty of Infrastructure Engineering, Dalian University of Technology, \\ Dalian 116024, China \\ Email: Jai.Vaze@,csiro.au
}

\begin{abstract}
There are numerous studies reported in literature which investigate the impacts of land use/land cover change and climate change on catchment water availability and there is sufficient evidence that afforestation can reduce streamflow substantially. The most commonly used methods for estimating impacts of plantations on water availability are catchment experiment method, statistical analysis method and the hydrological modelling method. Most of the studies reported in literature normally use either one of the sensitivity-based approach or a hydrological model with few actually comparing the impact results from these different approaches. This paper investigates the impacts of increase or decrease in plantations and climate variability on streamflow using two approaches: the sensitivity-based approach (seven methods) and the hydrological modelling approach (two models) for three medium sized catchments in Australia. The results from the different methods show that both plantation expansion/reduction and climatic differences can have major effects on catchment streamflow.
\end{abstract}

There is a small variability in the reduction or increase in streamflow estimated by the nine methods. The results from hydrological modelling are compared to those from the sensitivity-based methods. For all the three catchments, when compared to the hydrological modelling results, the Budyko based approaches overestimate the reductions in streamflow due to increase in plantations and underestimate the streamflow reductions due to drier climate. The results from the non-parametric approach are similar to those from hydrological modelling for the Crawford River and Darlot Creek catchments but the non-parametric approach underestimates the streamflow reductions due to increase in plantations and overestimates the streamflow reductions due to drier climate for the Tinana Creek catchment. When comparing the results for reduction in plantations for the Crawford River catchment, the Xinanjiang hydrological model underestimates the increase in streamflow due to reduction in plantations and overestimates the streamflow increase due to wetter climate when compared to the results from the other eight approaches. For the Darlot Creek catchment, the results from all the nine methods are similar and for the Tinana Creek catchment, the non-parametric approach underestimates the increase in streamflow due to reduction in plantations and overestimates the streamflow increase due to wetter climate when compared to the results from the other eight methods.

The results from this study show that the estimates of plantation impacts from the dynamic hydrological models are similar to those from the commonly used sensitivity-based approaches. The sensitivity-based approaches are only applicable where long term data sets are available and they only provide results at a mean annual time scale. The hydrological models simulate plantation impacted streamflow time series and so they can be used to estimate the relative contributions of land cover changes and climate change/variability at a daily, monthly or annual time-step. The outputs from the hydrological models can also be used to investigate the impacts of plantation expansion or reduction and climate change/variability on different runoff characteristics.

Keywords: Hydrological modelling, sensitivity-based approach, Runoff, Plantations, Afforestation, Climate change 
Vaze et al., Comparison of land-cover change and climate variability impacts on runoff using hydrological modelling and sensitivity-based approaches

\section{INTRODUCTION}

Catchment runoff is mainly controlled by climatic conditions, but it is also strongly influenced by land cover changes because of anthropogenic activities (Stoneman, 1993). There are numerous studies reported in literature which investigate the impacts of land use/land cover change and climate change on catchment water availability (Tomer and Schilling, 2009; Nangia et al., 2010) and there is sufficient evidence that afforestation can reduce streamflow substantially (Zhang et al., 2001; 2011). The total water use of plantations depends on the climate factors affecting water demand, the amount and seasonal distribution of rainfall, the hydrological factors affecting supply and the response of trees to climate, hydrology and plantation management. The most commonly used methods for estimating impacts of plantations on water availability are catchment experiment method and statistical analysis method and to a lesser extent the hydrological modelling method. The catchment experiment method is traditionally used for estimating the effect of forest management practices, such as afforestation and deforestation on catchment water availability (Hewlett et al., 1969). A number of catchment afforestation and deforestation studies have been conducted since 1960s and most of the results indicate that catchment runoff is significantly decreased after afforestation and obviously increase after deforestation. Van Lill et al. (1980) found that runoff from experimental catchments at Mokobulaan, Transvaal (South Africa) reduced from about the third year after afforestation, with a maximum apparent reduction in streamflow of between 300 and $380 \mathrm{~mm} / \mathrm{yr}$. Tuteja et al. (2007) showed that increase in plantation density in a large catchment in southeast Australia leaded to 16.4\%-27.8\% reduction in runoff from three different subcatchments (Delegate, Little Plains and Bombala).

It is important to separate and quantify the effects of increase or decrease in plantation area and climate variability/climate change so that it can be used for land use planning and water resources management. Although the catchment experiment method is very useful in quantifying the impacts of plantation expansion or reduction on catchment water yield, the method itself can not be used to partition relative contributions of land use/land cover change and climate change to catchment water availability. To achieve this, it needs to be combined with the statistical analysis method or the hydrological modelling method. The statistical analysis methods are usually based on mean annual numbers and so provide generalized relationships and do not consider species differences within the forest and grasslands, partial land use change and heterogeneity within the catchment. The hydrological modelling approach is more complex but can consider all these differences. The hydrological models simulate streamflow time series and so they can be used to estimate the relative contributions of land cover changes and climate change/variability at a daily, monthly or annual time-step. The outputs from the hydrological models (daily time series of impacted streamflow) can also be used to investigate the impacts of plantation expansion or reduction and climate change/variability on different runoff characteristics.

A number of studies reported in literature use fully-distributed and semi-distributed hydrological models to simulate impacts of land use changes on catchment water balance (Bultot et al., 1990; Elfert and Bormann, 2010). The use of fully-distributed hydrological models provides the capability to investigate the hydrological consequences with different spatial patterns of land use/land cover change. But the successful application of these models on medium to large size catchments is constrained by the difficulties associated with the parameterisation of these models. Compared to the distributed models, lumped conceptual rainfallrunoff models are easier to calibrate because of simpler model structure and less number of calibration parameters and provide a useful mean of quantifying the relative impacts of land cover change and climate variability on catchment water yield from medium to large size catchments (Vaze et al., 2004).

This paper presents and compare results from a widely used statistical approach, the sensitivity based approach (using seven methods, one non-parametric method, six Budyko-framework based methods) and the hydrological modelling approach (using two hydrological models, Xinanajiang and SIMHYD) to evaluate hydrological consequences of increase/decrease in plantations and climate variability for three medium size experimental catchments (700 to $1200 \mathrm{~km} 2$ ), which cover wide climatic regimes from eastern to southern Australia (Fig 1.). The first seven sensitivity based methods (non-parametric and Budyko-framework based) only provide results at mean annual time scale where as the hydrological modelling results are at a daily scale and they are aggregated to the mean annual time scale for comparison with those obtained from the other seven methods. The hydrological modelling is undertaken in two ways. Firstly, the two hydrological models are calibrated using streamflow data from the pre-afforestation period and the calibrated parameters are used to simulate runoff for the afforested period. The difference between the observed and model simulated runoff for the afforested period is used to quantify the impacts of the increase in plantations and climate variability between the two periods. Secondly, the two hydrological models are calibrated using streamflow data from the afforested period and the calibrated parameters are used to simulate runoff for the pre-afforestation period. The difference between the observed and model simulated runoff for the pre-afforestation period is 
Vaze et al., Comparison of land-cover change and climate variability impacts on runoff using hydrological modelling and sensitivity-based approaches

used to quantify the impacts of the reduction in plantations (pre-afforestation) and climate variability between the two periods. The seven sensitivity-based models are not calibrated, and the results from them are analysed in the same two ways as those from the two hydrological models.

\section{STUDY CATCHMENTS AND DATA}

The three experimental catchments (Crawford River (698km2), Darlot (760 km2) and Tinana Creek $(1174 \mathrm{~km} 2))$ are located in southeast Australia, which covers a wide range of climatic regimes (Fig. 1). All the three catchments are unregulated and they all have longterm reliable streamflow records. Large areas of plantations have been introduced in all the three catchments which make them suitable for this study.

All the three catchments used in this study have more than 20 years of continuous daily streamflow data spanning across the pre-afforestation and afforested periods. The streamflow data are checked for outliers

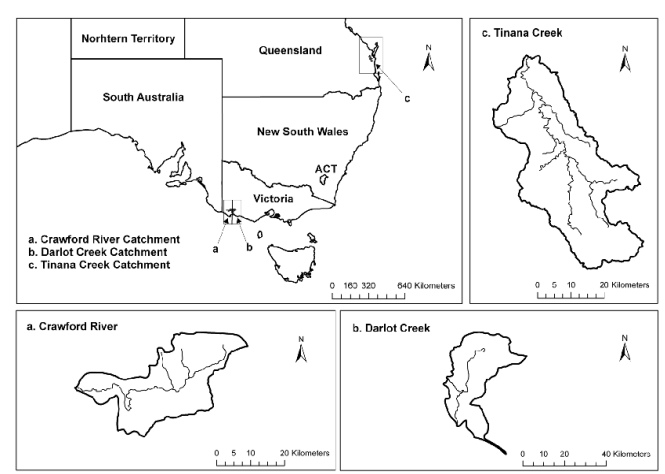

Figure 1. Location of the study catchments. and errors to be usable in hydrological modelling (Vaze et al., 2010). The source of the climate data (daily precipitation $(\mathrm{P})$ and APET used in this study is the 'SILO Data Drill' of the Queensland Department of Environment and Resource Management (www.derm.qld.gov.au/silo; Jeffrey et al., 2001).

Table 1. Cumulative plantation cover over time for the three study catchments

\begin{tabular}{|c|c|c|c|c|c|c|}
\hline \multirow{3}{*}{ Catchments } & \multirow{3}{*}{$\begin{array}{l}\text { Area } \\
\left(\mathrm{km}^{2}\right)\end{array}$} & \multicolumn{5}{|c|}{ Plantation cover } \\
\hline & & \multicolumn{2}{|c|}{ Pre-plantation } & \multicolumn{2}{|c|}{ Post-plantation } & \multirow{2}{*}{$\begin{array}{c}\text { Change } \\
(\%)\end{array}$} \\
\hline & & Period & $\begin{array}{c}\text { Percentage } \\
(\%)\end{array}$ & Period & $\begin{array}{c}\text { Percentage } \\
(\%)\end{array}$ & \\
\hline Crawford River & 698 & 1971-1997 & 3.6 & 2000-2006 & 24.6 & 21.0 \\
\hline Darlot Creek & 760 & 1984-1992 & 0.3 & $2000-2007$ & 13.7 & 13.4 \\
\hline Tinana Creek & 1174 & $1951-1970$ & 0.2 & $1990-1998$ & 23.7 & 23.5 \\
\hline
\end{tabular}

The plantation data for the three study catchments are obtained from the Bureau of Rural Science (BRS, 2009). Plantation expansion is the only significant land use change in these three experimental catchments over the study period. Table 1 provides details of cumulative plantation cover across the three catchments during the modelling period.

\section{METHODS}

\subsection{General Framework}

For a given catchment that is not subjected to regulation or diversion, the total change in mean annual streamflow between two independent periods with different landuse and climate characteristics can be estimated as

$\Delta Q_{t o t}=\overline{Q_{o b s}^{1}}-\overline{Q_{o b s}^{2}}$

where $\Delta Q_{\text {tot }}$ indicates the total change in mean annual streamflow, $\overline{Q_{o b s}^{1}}$ and $\overline{Q_{o b s}^{2}}$ are the mean annual measured streamflow during the first period and the second period, respectively.

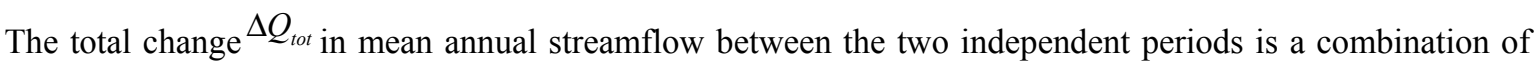
change in streamflow caused by the climatic differences between the two periods and change in streamflow due to the difference in catchment characteristics between the two periods. So, the total change in mean annual streamflow can be described as

$\Delta Q_{\text {tot }}=\Delta Q_{c c}+\Delta Q_{\text {clim }}$

where $\Delta Q_{c i}$ indicates the change in mean annual streamflow as a result of change in catchment characteristics between the two periods, $\Delta Q_{\text {clim is }}$ the change in mean annual streamflow because of climate change/climate variability between the two periods. In the catchments where there are no dam regulations or diversions, changes in catchment characteristics are mainly caused by changes in vegetation. Therefore, $\Delta Q_{c c}$ is approximately regarded as ${ }^{\Delta Q_{l c}}$, change in mean annual streamflow caused by change in vegetation variability. 
Vaze et al., Comparison of land-cover change and climate variability impacts on runoff using hydrological modelling and sensitivity-based approaches

To separate streamflow impacts caused by climate change and vegetation change, only $\Delta Q_{c \text { lim }}$ or $\Delta Q_{\text {lc }}$ needs to be quantified since $\Delta Q_{\text {wo is }}$ is available. A widely used approach to quantify $\Delta Q_{c \text { cim is }}$ the sensitivity-based

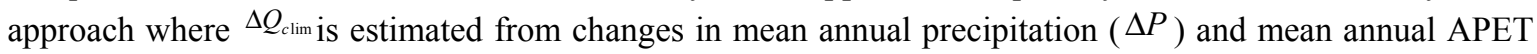
and their sensitivity coefficients. Another approach used to quantify $\Delta Q_{\text {climi }}$ is the hydrological modelling approach where hydrological models are first calibrated for one period, and then are applied to another independent period to quantify $\Delta Q_{\text {clim }}$.

\subsection{The Sensitivity-based approach}

As described above, ${ }^{\triangle Q_{\text {clim }} \text { is estimated from }} \triangle P$ and $\triangle A P E T$ using the following expression

$\Delta Q_{\text {clim }}=f_{P}^{\prime} \Delta P+f_{A P E T}^{\prime} \Delta_{A P E T}$

where $f_{P}^{\prime}$ is the sensitivity coefficient to mean annual precipitation and $f_{A P E T}^{\prime}$ is the sensitivity coefficient to mean annual APET. According to Zheng el al. (2009), Eq. (3) is re-written as

$\Delta Q_{c \lim }=\left(\varepsilon_{P} \Delta P / \bar{P}+\varepsilon_{A P E T} \triangle A P E T / \overline{A P E T}\right) \bar{Q}$, and $\varepsilon_{P}+\varepsilon_{A P E T}=1$

where $\mathcal{E}_{P}$ and $\varepsilon_{A P E T}$ are elasticity of streamflow with respect to $P$ and $A P E T$. Overbars indicate averages over a long-term period (including both periods). To estimate $\Delta Q_{\text {clim }}$ using Eq. (4), one needs to estimate precipitation elasticity of streamflow $\left({ }^{\mathcal{E}_{P}}\right)$. Sections 3.2.1 and 3.2.2 describe two widely used methods for estimating ${ }^{\varepsilon_{P}}$.

3.2.1 Non-parametric estimator of ${ }^{\mathcal{E}_{P}}$

Sankarasubramanian et al.(2001) developed a non-parametric method to estimate ${ }^{\varepsilon_{P}}$ as follow

$\mathcal{\varepsilon}_{P}=$ median $\left(\frac{\left(Q_{i}-\bar{Q}\right) / \bar{Q}}{\left(P_{i}-\bar{P}\right) / \bar{P}}\right)$

where $Q_{i}$ and $P_{i}$ are annual $\mathrm{P}$ and annual $\mathrm{Q}$ for the ith year.

\subsubsection{Budyko-framework estimator of ${ }^{\varepsilon_{P}}$}

In unregulated catchments where the average change in catchment water storage is negligible compared to the cumulative precipitation, evapotranspiration and runoff in a long period of over 5 years (Hobbins et al., 2001), catchment mean annual runoff can be estimated as

$\bar{Q}=\bar{P}-\bar{E}$

where $\bar{E}$ is catchment mean annual evapotranspiration. In the traditional Budyko-framework (Budyko, 1958), $\bar{E}$ is taken as a function of aridity index $(A I=\overline{A P E T} / \bar{P})$

$\bar{E}=\bar{P} f(A I)$

An analytical solution is derived to estimated ${ }^{\mathcal{E}_{P}}$ according to the Budyko-framework (Arora, 2002) as follow $\varepsilon_{P}=1+\frac{A I f^{\prime}(A I)}{1-f^{\prime}(A I)}$

According to the Eq. (8), ${ }^{\varepsilon_{P}}$ can be estimated for a given AI, once the form of $f(A I)$ is given (Li et al., 2012)..

\subsection{Hydrological modelling approach}

In this study, two lumped conceptual rainfall-runoff models, the Xinanjiang model and the SIMHYD model, are used to investigate the effects of vegetation changes on streamflow. The inputs of these two models are daily $\mathrm{P}$ and daily APET, and the output is daily runoff $\left(Q_{\text {sim }}\right)$. The generalised pattern search algorithm with linear inequality constraint in MATLAB (The Math Works, Inc.) is used to optimise the parameters of the two models. The models are calibrated by maximising the Nash-Sutcliffe Efficiency (NSE) (Nash and 
Vaze et al., Comparison of land-cover change and climate variability impacts on runoff using hydrological modelling and sensitivity-based approaches

Sutcliffe, 1970) of monthly streamflow. At the same time, a Water Balance Error (WBE) in percentage is considered as the linear inequality constraint compelling the total simulated streamflow to be within five percent of the total recorded streamflow (Vaze et al., 2011). The performance of both the conceptual rainfallrunoff models is evaluated in this study using the two criteria, NSE and WBE.

To quantify the relative effects of plantation expansion or reduction and climate variability, the model performance was evaluated for two separate cases. In case (1) the entire pre-afforestation period (before large scale plantations were introduced) for all the three catchments is used for model calibration. The calibrated parameter values are used to simulate streamflow for the afforested period. The observed and simulated streamflow over the afforested period is used to quantify the change in runoff due to plantation differences (afforestation) and climate variability between the pre-afforestation and afforested periods. In case (2) the entire afforested period (after large scale plantations were introduced) for all the three catchments is used for model calibration. The calibrated parameter values are used to simulate streamflow for the pre-afforestation period. The observed and simulated streamflow over the pre-afforestation period is used to quantify the change in runoff due to plantation differences and climate variability between the pre-afforestation and afforested periods.

\section{RESULTS AND DISCUSSION}

The box and whiskers plots in Fig. 2 show the percentage reduction in streamflow during the afforested period due to increase in plantations and drier climate estimated by the nine approaches. The reductions in streamflow due to increase in plantations when using the nine approaches range between $32 \%$ and $42 \%$ with a median of $40 \%$ for Crawford River catchment, between $22 \%$ and $34 \%$ with a median of $31 \%$ for Darlot Creek catchment and between $20 \%$ and $36 \%$ with a median of $32 \%$ for the Tinana Creek catchment. The corresponding reductions in streamflows due to climatic differences between the pre-afforestation and afforested periods when using the nine approaches range between $12 \%$ and $21 \%$ with a median of $13 \%$ for Crawford River catchment, between $15 \%$ and $27 \%$ with a median of $18 \%$ for Darlot Creek catchment and between 23\% and 40\% with a median of $27 \%$ for the Tinana Creek catchment. For all the three catchments, when compared to the hydrological modelling results, the Budyko based approaches overestimate the reductions in streamflow due to increase in plantations and underestimate the streamflow reductions due to the drier climate (afforested rainfall is slightly lower than the preafforestation rainfall and the afforested APET is slightly higher than the pre-afforestation APET). The results from the non-parametric approach are similar to those

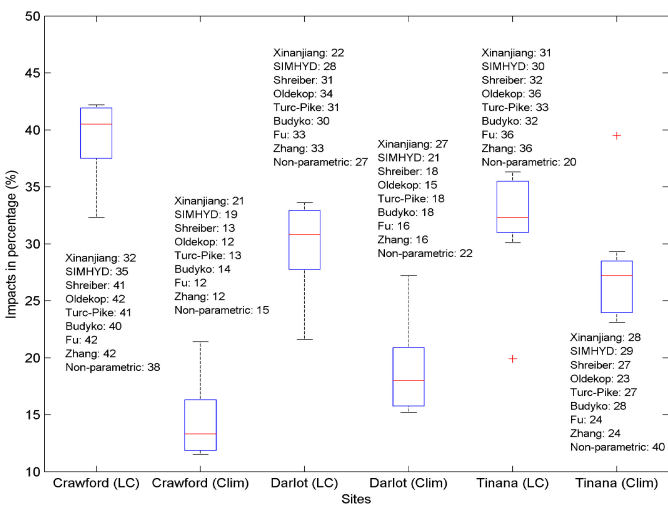

Figure 2. Percentage reduction in streamflow during the afforested period due to increase in plantations and drier climate estimated by the nine approaches.

from hydrological modelling for the Crawford River and Darlot Creek catchments. When compared to the hydrological modelling results for the Tinana Creek catchment, the non-parametric approach underestimates the streamflow reductions due to increase in plantations by about $10 \%$ and overestimates the streamflow reductions due to drier climate by about $10 \%$.

The box and whisker plots in Fig. 3 shows the percentage increase in streamflow during the preafforestation period due to reduction in plantations and wetter climate estimated by the nine methods. The increases in streamflow due to reduction in plantations when using the nine methods range between $69 \%$ and $92 \%$ with a median of $88 \%$ for Crawford River catchment, between $53 \%$ and $68 \%$ with a median of $60 \%$ for Darlot Creek catchment and between $49 \%$ and $90 \%$ with a median of $86 \%$ for the Tinana Creek catchment. The corresponding increases in streamflows due to wetter climatic in the pre-afforestation period when using the nine methods range between $25 \%$ and $48 \%$ with a median of $28 \%$ for Crawford River catchment, between $27 \%$ and $42 \%$ with a median of $35 \%$ for Darlot

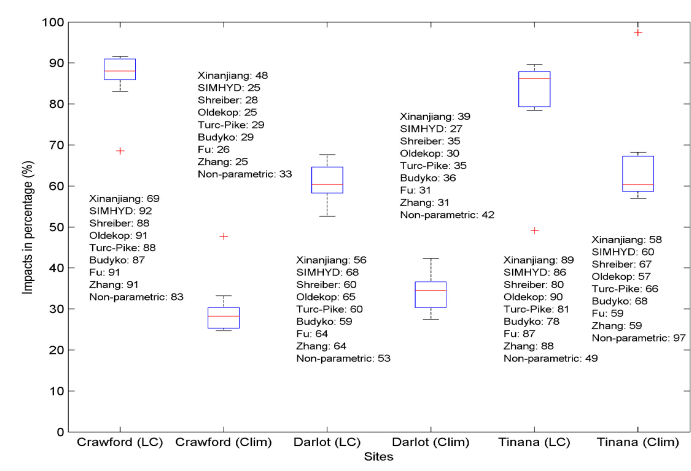

Figure 3. Percentage increase in streamflow during the pre-afforestation period due to reduction in plantations and wetter climate estimated by the nine approaches. 
Vaze et al., Comparison of land-cover change and climate variability impacts on runoff using hydrological modelling and sensitivity-based approaches

Creek catchment and between $57 \%$ and $97 \%$ with a median of $60 \%$ for the Tinana Creek catchment. For the Crawford River catchment, the Xinanjiang model underestimates the increase in streamflow due to reduction in plantations and overestimates the streamflow increase when compared to the results from the other eight methods. For the Darlot Creek catchment, the results from all the nine methods are similar and for the Tinana Creek catchment, the non-parametric approach underestimates the increase in streamflow due to reduction in plantations and overestimates the streamflow increase when compared to the results from the other eight methods.

There is a small variability in the reduction or increase in streamflow estimated by the nine methods with the seven Budyko framework based methods providing very similar results. This is to be expected as these seven methods use the same underlying concept with little differences in the way the climate elasticity coefficients are estimated. The results from the two hydrological models are very similar for all the three catchment for increase as well as decrease in plantations except for the Crawford River catchment where the Xinanjiang model underestimates the increase in streamflow due to reduction in plantations and overestimates the streamflow increase due to wetter climate when compared to the results from the other eight methods.

The analysis shows that the plantation impact results from the two hydrological models are similar to those from the commonly used sensitivity-based approaches. The sensitivity-based approaches are only applicable where long term data sets are available and they only provide results at a mean annual time scale. The hydrological models simulate plantation impacted streamflow time series and so they can be used to estimate the relative contributions of land cover changes and climate change/variability at a daily, monthly or annual time-step. The outputs from the hydrological models (daily time series of impacted streamflow) can also be used to investigate the impacts of plantation expansion or reduction and climate change/variability on different runoff characteristics.

\section{CONCLUSIONS}

There is sufficient evidence that afforestation can reduce streamflow substantially and there are numerous studies reported in literature which investigate the impacts of land use/land cover change and climate change on catchment water availability. Most of the studies reported in literature normally investigate the impacts of plantation expansion on streamflow. But there are barely any studies which investigate the impacts of plantation expansion as well as plantation reduction for the same catchments. All these studies normally use either one of the sensitivity-based approaches or one of the hydrological models with few actually comparing the impact results from these different approaches. This paper investigates the impacts of land-cover change and climate variability on streamflow using observed data and nine different methods (one non-parametric method, six Budyko framework based methods and two conceptual hydrological models) for three medium sized catchments in Australia. The results from the nine methods show that both plantation expansion/reduction and climatic differences can have major effects on catchment streamflow.

The results from hydrological modelling are compared to those from the seven sensitivity-based methods. For all the three catchments, when compared to the hydrological modelling results, the Budyko framework based methods overestimate the reductions in streamflow due to increase in plantations and underestimate the streamflow reductions due to drier climate. The results from the non-parametric method are similar to those from hydrological modelling for the Crawford River and Darlot Creek catchments but the non-parametric method underestimates the streamflow reductions due to increase in plantations and overestimates the streamflow reductions due to climate variability for the Tinana Creek catchment. When comparing the results for plantation reduction, for the Crawford River catchment, the Xinanjiang model underestimates the increase in streamflow due to reduction in plantations and overestimates the streamflow increase when compared to the results from the other eight methods. For the Darlot Creek catchment, the results from all the nine methods are similar and for the Tinana Creek catchment, the non-parametric approach underestimates the increase in streamflow due to reduction in plantations and over estimates the streamflow when compared to the results from the other eight methods.

The results from this study show that the estimates of plantation impacts from the hydrological models are similar to those from the commonly used sensitivity-based approaches. The sensitivity-based approaches are only applicable where long term data sets are available and they only provide results at a mean annual time scale. The hydrological models simulate plantation impacted streamflow time series and so they can be used to estimate the relative contributions of land cover changes and climate change/variability at a daily, monthly or annual time-step. The outputs from the hydrological models can also be used to investigate the impacts of plantation expansion or reduction and climate change/variability on different runoff characteristics. 
Vaze et al., Comparison of land-cover change and climate variability impacts on runoff using hydrological modelling and sensitivity-based approaches

\section{ACKNOWLEDGMENTS}

This work was carried out in the Water for a Healthy Country National Research Flagship at the Australian Commonwealth Scientific and Research Organization (CSIRO).

\section{REFERENCES}

Arora, V.K., 2002. The use of the aridity index to assess climate change effect on annual runoff. Journal of Hydrology, 265(1-4): 164-177.

Budyko, M.I., 1958. The Heat Balance of the Earth's Surface, translated from Russian by N. A. Stepanova, 259 pp. U.S. Dep. of Commer., Washington.

Bultot, F., Dupriez, G.L., Gellens, D., 1990. Simulation of land use changes and impacts on the water balance- A case study for Belgium. Journal of Hydrology 114 (3-4), 327-348.

Elfert, S., Bormann, H., 2010. Simulated impact of past and possible future land use changes on the hydrological response of the Northern German lowland 'Hunte' catchment. Journal of Hydrology 383 (34), 245-255.

Hewlett, J.D., Lull, H.W., Reinhart, K.G., 1969. In defense of experimental watersheds. Water Resources Research. doi:10.1029/WR005i001p00306.

Hobbins, M.T., Ramirez, J.A. and Brown, T.C., 2001. The complementary relationship in estimation of regional evapotranspiration: An enhanced Advection-Aridity model. Water Resources Research, 37(5): 1389-1403.

Jeffrey, S.J., Carter, J.O., Moodie, K.B., Beswick, A.R., 2001. Using spatial interpolation to construct a comprehensive archive of Australian climate data, Environmental Modelling \& Software 16 (4), 309-330.

Li, H, Zhang, Y., Vaze, J., Wang, B. 2012. Separating effects of vegetation change and climate variability using hydrological modelling and sensitivity-based approaches. Journal of Hydrology, Volume 420, pp 403-418, doi: 10.1016/j.jhydrol.2011.12.033.

Nangia, V., Mulla, D.J., Gowda, P.H., 2010. Precipitation changes impact stream discharge, nitrate nitrogen loads more than agricultural management changes. J. Environmental Quality, 39, 2063-2071.

Nash, J.E., Sutcliffe, J.V., 1970. River flow forecasting through conceptual models part I - A discussion of principles. Journal of Hydrology 10 (3), 282-290.

Sankarasubramaniam A, Vogel RM, and Limburner JF., 2001. Climate elasticity of streamflow in the United States. Water Resources Research, 37:1771-1781.

Stoneman, G.L., 1993. Hydrological response to thinning a small jarrah (Eucalyptus marginata) forest catchment. Journal of Hydrology 150 (2-4), 393-407.

Tomer, M.D., Schilling, K.E., 2009. A simple approach to distinguish land-use and climate-change effects on watershed hydrology. Journal of Hydrology 376 (1-2), 24-33.

Tuteja, N.K., Vaze, J., Teng, J., Mutendeudzi, M., 2007. Partitioning the effects of pine plantations and climate variability on runoff from a large catchment in southeastern Australia. Water Resources Research. doi:10.1029/2006WR005016.

Van Lill, W.S., Kruger, F.J., Van Wyk, D.B., 1980. The effect of afforestation with Eucalyptus Grandis Hill ex Maiden and Pinus Patula Schlecht. et Cham. on streamflow from experimental catchments at Mokobulaan, Transvaal. Journal of Hydrology 48 (1-2), 107-118.

Vaze, J., Barnett, P., Beale, G.T.H., Dawes, W., Evans, R., Tuteja, N.K., Murphy, B., Geeves, G., and Miller, M., 2004. Modelling the effects of landuse change on water and salt delivery from a catchment affected by dryland salinity in south-east Australia, Hydrological Processes, Vol. 18, pp. 1613 - 1637.

Vaze, J., Chiew, F. H. S., Perraud, JM., Viney, N., Post, D. A., Teng, J., Wang, B., Lerat, J., Goswami, M., 2010. Rainfall-runoff modelling across southeast Australia: datasets, models and results. Australian Journal of Water Resources, Vol 14, No 2, pp. 101-116.

Vaze, J., Davidson, A., Teng, J., Podger, G., 2011. Impact of climate change on water availability in the Macquarie-Castlereagh river basin in Australia. Hydrological Processes, Vol 25, Issue 16, 2597-2612, DOI: $10.1002 /$ hyp.8030.

Vaze, J., Post, D. A., Chiew, F. H. S., Perraud, J.-M., Teng, J., Viney, N., 2011. Conceptual Rainfall-Runoff Model Performance with Different Spatial Rainfall Inputs, Journal of Hydrometeorology, Vol. 12, No. 5. pp 1100-1112, doi: 10.1175/2011JHM1340.1.

Zhang, L., W. R. Dawes, and G. R. Walker, 2001. Response of mean annual evapotranspiration to vegetation changes at catchment scale. Water Resources Research, 37 (3):701-708.

Zhang, L., F. Zhao., Y. Chen, and R. Dixon, 2011. Estimating effects of plantation expansion and climate variability on streamflow for catchments in Australia. Water Resources research, Vol. 47, W12539.

Zheng, H.X. et al., 2009. Responses of streamflow to climate and land surface change in the headwaters of the Yellow River Basin. Water Resources Research, 45., W00A19, doi: 1029/2007WR006665. 